\title{
Robert Hill Perfectionism Scale Standardization among University Students
}

\author{
Shadi Ahadifar ${ }^{1}$, Mojtaba Habibi ${ }^{2}$, Mani B. Monajemi ${ }^{3}$
}

\section{ABSTRACT}

Objective: This survey was conducted regarding observe validity, reliability and standardization of Robert Hill's perfectionism scale among the university students.

Materials and Methods: The statistical population of this survey included all bachelor students of Tehran Azad University (Central branch) in academic year of 2009-2010 with the age between20 to 35. Among this statistical population via random cluster sampling, 500 students (310women and 190men) were chosen. In this survey, regarding assessing perfectionism scale reliability, factor analysis method was used. Before performing factor analysis, sampling adequacy was proved by rejecting zero hypotheses based on correct matrix homology in society by Bartlett test. Hence, implementing factor analysis was justifiable. In order to check the validity of Hill perfectionism scale, Cronbach's alpha coefficient was used and after deleting unsuitable questions (4-15-19), scale validity coefficient of 0/921 was gained which indicates that perfectionism scale is having high validity. In order to determine the construct reliability, factor analysis was used. Assessment of perfectionism scale was conducted through the principal component analysis and orthogonal rotation. According to results from factor analysis, among 56 perfectionism questions, 6 factors were extracted which justified 47/0 percent of all variables. Factor matrix showed: the first factor is having the highest factor power and share comparing to other factors. In current survey, questions $(59,24,2,11,36,44,34,47,31,18,32,71)$ were complex questions, as they tended to have power in various factors. In order to determine perfectionism scale norm for the students, questionnaire scores was determined. Accordingly, perfectionism questionnaire contents were graded based on four scales' items from agree to disagree with grades 1 to 4 .

Results: Hill perfectionism scale is having proper psychometric features to be used in Iran society.

Keywords: Perfectionism, Standardization, University Students

\footnotetext{
${ }^{1}$ Islamic Azad University of Tehran, Department of Psychology

${ }^{2}$ Ph.D. in Health Psychology, Assistant Professor at Family Research institute, Shahid Beheshti University, (mo_habibi@sbu.ac.ir)

${ }^{3}$ Department of Clinical Psychology, University of Tehran, Tehran, Iran (mani.b.monajemi@warwickgrad.net, mani.b.monajemi@ut.ac.ir)

(C) 2015 I S Ahadifar, M Habibi, M B. Monajemi; licensee IJIP. This is an Open Access Research distributed under the terms of the Creative Commons Attribution License (http://creativecommons.org/licenses/by/2.0), which permits unrestricted use, distribution, and reproduction in any Medium, provided the original work is properly cited.
} 
Bernz presented perfectionism concept for the first time as one-dimensional construct. With respect to one-dimensional approach, perfectionist individuals are after flawless results under any circumstances and this may cause them several damages (asserted by Jamshidi, Chari, Haghighat and Razmi 2009). Perfectionism is a collection of very high standards for the performance along with self-negative assessment and criticism (Abolghasemi, Ahmadi Amoli and Kiamarsi 2007).The perfectionist assesses himself in light of the strict criteria and feels emotionally distressed(Alden \& Beiling1993 asserted by Atari and Kareshki 2013).Adler (1963) considered some of the perfectionism aspects advantageous for human and claimed: the attempt to reach perfectionism is innate and it is considered as a part of life and without it life is impossible. From Adler`s point of view, attempt to reach perfectionism would be positive and constructive, while it is consistent with social interests and could maximize individual's potential. On the other hand, it would be destructive and negative while the individual utilize it to dominate the others (asserted by Beshaarat, Karami and Ezheyie 2010)

Different researchers distinguished positive and negative aspects of perfectionism by terms such as: active perfectionism against non-active perfectionism, enabling perfectionism against disabling perfectionism, lucid perfectionism against improper perfectionism, and normal perfectionism against neurotic perfectionism. (Parker1997, asserted by Besharat et al 2010).With respect to this notion, Estaberbelieves that positive and negative aspects of perfectionism should be differentiated. Hence, positive aspect may stands for being perfect and tendency for flawless organization, while negative aspect is about preoccupation and worrying about one self's mistakes.

Although the researchers made diverse tools in order to assess perfectionism, in a survey conducted by (Shafran \& Mansel2001), they noticed that available tools might not be able to explain perfectionism precisely. Thus, need for precise and standard tool regarding assessment of perfectionism seems to be essential. Generally, perfectionism theories and surveys leads to different and sometimes contradictory results. Many researchers believe that it is vital to maintain various tools and questionnaires for different samples with various social/cultural backgrounds (Pasha Sharifi et al 2011). Henceforth, it is worth mentioning that among provided scales regarding assessment of perfectionism, Frost et al scale and Hoit and flat `s scale are more supported in researches comparing to other scales. Although, each of these scales assesses rather different concepts, some of the researchers combined aforementioned scales in order to reach more comprehensive results. Albeit, this combination led to semantic similarity and overlap in some cases (asserted by Jamshidi et al 2009). In response to this necessity, Hill and Colleagues (2004) developed a tool, which could involve all aforementioned factors that former approaches proposed. This tool is in consistent with perfectionism one-dimensional definition and also perfectionism definition as two-dimensional structures and perfectionism multi-dimensional definition (asserted by Pasha Sharifi et al 2011). 
It is worth mentioning that hill perfectionism inventory have been applied on students sample in Shiraz/Iranby Jamshidi and Colleagues(1388)but according to literatures, factor analysis is better to be performed among different samples (asserted by Pasha Sharifi et al2011). Therefore, this survey is conducted with the goal to observe Robert Hill validity, reliability and standardization of perfectionism scale among Islamic Azad University students of central Tehran.

\section{METHOD}

The statistical population of this research involved all men and women in bachelor period of university in Tehran/Iran between 2009-2010,who were studying in Islamic Azad University of Tehran(Central Branch) with age range from 20 to 35.In this research, factor analysis method was used in order to observe the reliability of perfectionism scale and as the sample capacity in all multi-variables analysis shouldn't be less than 500(Homan 2001 page 380), 500 people were chosen through cluster random sampling. Sampling unit was university. According to cluster random sampling, 500 individuals (310 women, $190 \mathrm{men}$ ) answered the questionnaires. Questionnaire was conducted in a group form among the university students. Furthermore, the instruction of answering the questionnaire was written on the first page. Regarding more emphasis the instruction was explained to the respondents orally.

\section{Research tools}

This questionnaire includes 59 questions and Robert Hill and colleagues made itin 2004. The most appropriate and the best method to scoring Hill perfectionism scale is using Likert model. Items are rated using 4-point Likert scale, whereby 1=Strongly disagree and 4=Strongly agree. High score in this scale indicates high perfectionism sign and low score indicates low perfectionism sign.

In order to use this scale in this survey, mentioned questionnaire was translated from English to Persian and after modifying the questions, the questionnaire was prepared for initial implementation. In next level, the initial form was implemented three times and each time on 50 university students. After analyzing and revising the questions, ultimately the final form was prepared.

\section{RESULTS}

To assess validity coefficient of perfectionism inventory, Cronbach's alpha coefficient was used and after ruling out improper questions (4-15-55), validity of 0/921 was attained, which indicates: perfectionism scale is having high creditability.

In order to determine construct reliability of perfectionism scale, factor analysis was used. Observing factor structure of perfectionism scale was done by the principal component analysis and orthogonal rotation. In this survey, KMO (Kaiser Meyer Olkin) Index value of sampling adequacy was 0/822 and Bartlett test of sphere city was equal to 12979/618, which was meaningful statistically and according to both criteria, it could be concluded that: implementing factor analysis would be persuasive based on the resulting correlation matrix in sample group. 
Furthermore, determinant rate of correlational matrix was equal to 0/0000012, which indicated: factors extraction is possible according to data. Furthermore, to determine the number of the factors, Scree sloping chart was used and 6 factors have been used regarding more observation. Table 1 shows the amount of specific values, the percentage of variance explained by each factor and the density of factors.

Table1- the percentage of variance explained by each factor and the density of factors

\begin{tabular}{cccc}
\hline Factor & Specific value & Variance percentage & Density percentage \\
1 & 11.299 & 20.2 & 20.2 \\
2 & 5.399 & 9.6 & 29.8 \\
3 & 2.889 & 5.2 & 35.0 \\
4 & 2.451 & 4.4 & 39.4 \\
5 & 2.265 & 4.0 & 43.4 \\
6 & 2.029 & 3.6 & 47.0 \\
\hline
\end{tabular}

According to Table-No1,6 factors were extracted in this study. Respectively, factors justify $20 / 2 \%, 9 / 6 \%, 5 / 2 \%, 4 / 4 \%, 4 / 0 \%$ and $3 / 6 \%$ of variance. Other factors maintain inconsiderable share in explaining variance. Therefore, according to explained variance rate, 6 factors are proper for extraction. Considerably, from 56 questions about perfectionism, 6 factors are extracted that explains 47/0 percent of all variables. The special value of 6 factors is shown in Table-No1.

After determining 6 factors and according to explained variance value,in order to reach simple structure and interpret them; orthogonal rotation was implemented with respect to 6 factors. Table-No2 shows simple structure matrix.

Table2-Simple structure matrix for the factors

\begin{tabular}{lcccccc}
\hline Question & factor1 & factor2 & factor3 & factor4 & factor5 & factor6 \\
\hline Q46 & 742 & & & & & \\
Q10 & 668 & & & & \\
Q26 & 661 & & & & \\
Q39 & 647 & & & & \\
Q46 & 640 & & & & \\
Q57 & 638 & & & & \\
Q53 & 612 & & & & \\
Q14 & 590 & & & & \\
Q50 & 588 & & & & \\
Q23 & 563 & & & & \\
Q48 & 561 & & & & \\
Q42 & 528 & & & & \\
Q30 & 518 & & & & \\
Q32 & 516 & & & & \\
Q38 & 504 & & & &
\end{tabular}


Robert Hill Perfectionism Scale Standardization among University Students

\begin{tabular}{|c|c|c|c|c|c|c|}
\hline Q7 & 501 & & & & & \\
\hline Q47 & 476 & -438 & & & & \\
\hline Q31 & 440 & -405 & & & & \\
\hline Q18 & 433 & 400 & & & & \\
\hline Q59 & 409 & 388 & & & -332 & \\
\hline Q9 & & 648 & & & & \\
\hline Q51 & & 642 & & & & \\
\hline Q20 & & 617 & & & & \\
\hline Q17 & & 615 & & & & \\
\hline Q45 & & 563 & & & & \\
\hline Q12 & & 550 & & 411 & & \\
\hline Q24 & 507 & 536 & & & & \\
\hline Q8 & & 535 & & & & \\
\hline Q28 & & 508 & & & & \\
\hline Q25 & & 500 & & & & \\
\hline Q37 & & 424 & & 412 & & \\
\hline Q35 & & & 801 & & & \\
\hline Q22 & & & 626 & & & \\
\hline Q27 & & & 569 & & & \\
\hline Q43 & & & 486 & & & \\
\hline Q40 & & & 471 & & & \\
\hline Q44 & & 488 & 454 & & & \\
\hline Q36 & & 436 & 440 & 388 & & \\
\hline Q2 & & 403 & 412 & & & \\
\hline Q11 & & & 350 & 337 & & \\
\hline Q56 & & & 329 & & & \\
\hline Q54 & & & & 682 & & \\
\hline Q52 & & & & 603 & & \\
\hline Q58 & & & & 601 & & \\
\hline Q21 & & & & 510 & & \\
\hline Q34 & 332 & & & 397 & & \\
\hline Q6 & & & & 317 & & \\
\hline Q33 & & & & & 592 & \\
\hline Q29 & & & & & 587 & \\
\hline Q3 & & & & & 509 & \\
\hline Q16 & & & & & 472 & \\
\hline Q13 & & & & & 464 & \\
\hline Q41 & & & & & & 648 \\
\hline Q19 & & & & & & -509 \\
\hline Q1 & & & & & & 411 \\
\hline Q5 & & & & & & 378 \\
\hline
\end{tabular}


As it can be inferred from Table-No2, questions 59,24,37,2,11,36,44,34,47,31,18,32 and 71 are complicated questions, as they maintain several meaning and they can be interpreted in various ways. The group of questions which are correlated with one factor and together they form a retail test is as following:

First factor: Question number 49, 10, 26, 39, 46, 57, 53, 14, 50, 23, 48, 42, 32, 30, 38, 7, 47, 31, 18 and 59

Second factor: Question number 9, 51, 20, 17, 45, 12, 24, 8, 28, 25 and 37

Third factor: Question number35, 22, 27, 43, 40, 44, 36, 2, 11 and 56

Fourth factor: Question number 54, 52, 58, 21, 34 and 6

Fifth factor: Question number 23, 29, 3, 16, 13

Sixth factor: Question number

1- Fear of Mistakes

2- Tendency toward being flawless

3- Performance personal criteria

4- Fulfilling parent`s expectations

5- Necessity to progress

6- Supremacy or tendency toward dominating others

In order to determine perfectionism scale's norm for the students, questionnaire's scores were estimated. Accordingly, perfectionism questionnaire notes were graded based on four-point Likert scale from agree to disagree from 1 to 4 scores. The score`s statistical features attained from the questionnaire for each factor and whole questionnaire is illustrated in Table-No3.

\section{Table3-perfectionism score`s statistical features}

\begin{tabular}{lllrrrrrrr}
\hline Factor & means median & $\begin{array}{r}\text { view } \\
\text { standard } \\
\text { Deviation }\end{array}$ & $\begin{array}{c}\text { mean } \\
\text { error }\end{array}$ & $\begin{array}{c}\text { tensity tensity } \\
\text { mean }\end{array}$ & $\begin{array}{c}\text { skewness } \\
\text { error }\end{array}$ \\
\hline 1 & $2 / 09$ & $2 / 00$ & $2 / 00$ & $0 / 50$ & $0 / 03$ & $0 / 79$ & $0 / 12$ & $0 / 14$ & $0 / 24$ \\
2 & $2 / 77$ & $2 / 82$ & $2 / 91$ & $0 / 54$ & $0 / 03$ & $-0 / 60$ & $0 / 12$ & $0 / 10$ & $0 / 24$ \\
3 & $2 / 57$ & $2 / 70$ & $2 / 70$ & $0 / 49$ & $0 / 03$ & $-0 / 39$ & $0 / 12$ & $0 / 54$ & $0 / 24$ \\
4 & $2 / 52$ & $2 / 50$ & $2 / 33$ & $0 / 51$ & $0 / 03$ & $0 / 11$ & $0 / 12$ & $0 / 21$ & $0 / 24$ \\
5 & $2 / 84$ & $2 / 80$ & $2 / 60$ & $0 / 46$ & $0 / 02$ & $-0 / 21$ & $0 / 12$ & $0 / 10$ & $0 / 24$ \\
6 & $2 / 88$ & $2 / 75$ & $2 / 75$ & $2 / 75$ & $0 / 02$ & $-0 / 22$ & $0 / 12$ & $0 / 26$ & $0 / 24$ \\
Total & $2 / 48$ & $2 / 50$ & $2 / 48$ & $0 / 36$ & $0 / 02$ & $0 / 20$ & $0 / 12$ & $0 / 13$ & $0 / 24$ \\
\hline
\end{tabular}

As Table-No3 indicates: factor 3 (performance personal criteria) maintains skewness to left. The first factor (fear about the mistakes) and also the second factor (trend to be flawless) have skewness. The factors4 (fulfilling parent`s expectations), the factor 5(necessity to progress), 6(supremacy) and also the whole questionnaire don`t have meaningful difference with normal distribution. 
Table-No4 is discussing frequency and percentage values of perfectionism plan for the whole questionnaire

Table4 Frequency and percentage values of perfectionism plan for the whole questionnaire

\begin{tabular}{|c|c|c|c|c|c|c|c|c|c|c|c|}
\hline \multicolumn{2}{|c|}{ Cumulative } & Frequency & \multicolumn{2}{|c|}{ Frequency } & \multirow{2}{*}{\begin{tabular}{|c|} 
Score \\
2
\end{tabular}} & \multicolumn{2}{|c|}{ Cumulative } & \multirow{2}{*}{$\begin{array}{c}\text { Frequency } \\
\mathbf{0}\end{array}$} & \multicolumn{3}{|c|}{ Frequency Score } \\
\hline 84 & $\mathbf{0}$ & 1 & $2 / 82$ & 38 & & 6 & $2 / 32$ & & $\mathbf{0}$ & 1 & \\
\hline \multicolumn{12}{|l|}{$1 / 50$} \\
\hline 85 & 1 & 5 & $2 / 84$ & 38 & $\mathbf{0}$ & 1 & $2 / 36$ & 1 & $\mathbf{0}$ & 1 & \\
\hline \multicolumn{12}{|l|}{$1 / 55$} \\
\hline 86 & 1 & 4 & $2 / 86$ & 39 & 1 & 2 & $2 / 38$ & 1 & 1 & 2 & $1 / 57$ \\
\hline 87 & 1 & 3 & $2 / 88$ & 39 & 1 & 2 & $2 / 39$ & 1 & 0 & 1 & \\
\hline \multicolumn{12}{|l|}{$\mathbf{1} / \mathbf{6 1}$} \\
\hline 88 & 1 & 3 & 2/89 & 41 & 1 & 5 & $2 / 41$ & 4 & 2 & 9 & \\
\hline \multicolumn{12}{|l|}{$1 / 89$} \\
\hline 89 & 1 & 4 & $2 / 91$ & 42 & 1 & 4 & $2 / 43$ & 4 & 1 & 3 & \\
\hline \multicolumn{12}{|l|}{$1 / 91$} \\
\hline 89 & 1 & 3 & 2/93 & 43 & 1 & 5 & $2 / 45$ & 7 & 2 & 9 & \\
\hline \multicolumn{12}{|l|}{$1 / 93$} \\
\hline 91 & 2 & 3 & 2/95 & 44 & 2 & 6 & $2 / 46$ & 7 & 1 & 2 & \\
\hline \multicolumn{12}{|l|}{ 1/95 } \\
\hline 92 & 1 & 5 & $2 / 96$ & 49 & 5 & 5 & $2 / 48$ & 8 & 1 & 2 & \\
\hline \multicolumn{12}{|l|}{$1 / 98$} \\
\hline 93 & 1 & 4 & $2 / 98$ & 52 & 3 & 3 & $2 / 50$ & 8 & 1 & 2 & \\
\hline \multicolumn{12}{|l|}{$2 / 00$} \\
\hline 94 & 0 & 1 & $3 / 02$ & 54 & 3 & 3 & $2 / 52$ & 9 & 1 & 3 & \\
\hline \multicolumn{12}{|l|}{$2 / 02$} \\
\hline 94 & $\mathbf{0}$ & 1 & $3 / 04$ & 57 & 3 & 3 & $2 / 54$ & 10 & 1 & 3 & \\
\hline \multicolumn{12}{|l|}{$2 / 04$} \\
\hline 94 & 0 & 1 & $3 / 05$ & 59 & 3 & 3 & $2 / 55$ & 10 & 2 & 2 & \\
\hline \multicolumn{12}{|l|}{ 2/05 } \\
\hline 94 & $\mathbf{0}$ & 1 & $3 / 07$ & 63 & 3 & 3 & $2 / 57$ & 12 & 2 & 9 & 2/07 \\
\hline \multirow[t]{2}{*}{95} & 1 & 2 & $3 / 09$ & 66 & 3 & 3 & $2 / 59$ & 15 & & 5 & \\
\hline & 9 & & $2 / 09$ & & & & & & & & \\
\hline 95 & 1 & 2 & 3/11 & 69 & 3 & 3 & $2 / 61$ & 19 & 2 & 19 & $2 / 11$ \\
\hline \multirow[t]{2}{*}{96} & 1 & 2 & 3/18 & 72 & 2 & 3 & $2 / 63$ & 22 & & 1 & \\
\hline & 9 & & $2 / 13$ & & & & & & & & \\
\hline \multirow[t]{2}{*}{96} & 1 & 2 & $3 / 21$ & 74 & 0 & 2 & $2 / 64$ & 23 & & 2 & \\
\hline & 5 & & $2 / 14$ & & & & & & & & \\
\hline \multirow[t]{2}{*}{97} & 0 & 1 & $3 / 23$ & 74 & 1 & 0 & $2 / 66$ & 25 & & 1 & \\
\hline & 7 & & $2 / 16$ & & & & & & & & \\
\hline
\end{tabular}


Robert Hill Perfectionism Scale Standardization among University Students

\begin{tabular}{lllllllllllll}
97 & 0 & 1 & $3 / 25$ & 75 & 1 & 1 & $2 / 68$ & 26 & 2 & 4 & $2 / 18$ \\
97 & 0 & 1 & $3 / 25$ & 76 & 1 & 1 & $2 / 70$ & 27 & & 1 & 5 \\
$2 / 20$ & & & & & & & & & & & \\
99 & 2 & 6 & $3 / 29$ & 77 & 1 & 1 & $2 / 71$ & 28 & & 1 & 3 \\
$2 / 21$ & & & & & & & & & & & \\
99 & 1 & 2 & $3 / 32$ & 78 & 1 & 1 & $2 / 73$ & 31 & & 4 & 14 \\
$2 / 23$ & & & & & & & & & & & \\
99 & 0 & 1 & $3 / 34$ & 79 & 1 & 1 & $2 / 75$ & 31 & 0 & 1 & $2 / 25$ \\
100 & 0 & 1 & $3 / 39$ & 81 & 3 & 3 & $2 / 77$ & 33 & 2 & 6 & \\
$2 / 27$ & & & & & & & & & & & \\
100 & 0 & 1 & $3 / 46$ & 82 & 1 & 1 & $2 / 79$ & 35 & 3 & 10 & \\
$2 / 29$ & & & & & & & & & & & \\
100 & 0 & 1 & $3 / 46$ & 84 & 1 & 1 & $2 / 80$ & 37 & 1 & 5 & \\
$2 / 30$ & & & & & & & & & & & \\
\hline
\end{tabular}

For perfectionism scale scores, category norm was provided with four levels of agreement based on breaking down normal distribution of scores. This category norm is presented on table 5 .

Table5-category norm of perfectionism scores

Category Score`s mean Raw scores total

Agree3/50 and higher

Relatively agree2/50-3/49

Relatively disagree1/50-2/49

Disagree1/00-1/49
196 and higher

140-195

84-139

83-56

\section{DISCUSSION AND CONCLUSION}

This survey is conducted to observe practicality, validity, reliability and standardization of Robert Hill`s perfectionism scale among bachelor university students of Islamic Azad University of Tehran. The results of this survey are gained by using factor analysis method and analyzing main factors and also perceptive observation of the hypothesis as following:

The first factor of Hill perfectionism scale, which is worrying about mistakes, is strongly correlated with 20 questions. Accordingly, Hamuchek divides perfectionism into to subtypes: Normal and Neurotic. He believes that neurotic perfectionism is experiencing high level of anxiety about the mistakes and having fear of the other`s judgment. The second factor is correlated with 11 questions and shows tendency toward flawlessness. In this regard, Hornai 1934 defines perfectionism as neurotic tendency to be meticulous and flawless. Accordingly, individuals consider smallest sin as unforgivable sin and anxiously, they expect antagonistic consequences regarding their actions. Hollender(1965) asserts: perfectionism shows the individual's interest to understand surrounding area (all or nothing) which could lead to perfect failure or success. The third factor is correlated with 10 questions and shows performance 
personal criteria. From Frost and Colleague's point of view, the second dimension of perfectionism includes performance personal criteria and most theorists usually consider this field as the central sign of the perfectionism. As perfectionist tend to maintain high level expectations which cannot usually be satisfying. Furthermore, Hewit \& Flett(1990)believe that perfectionism is individual`s propensity to maintain the collection of extreme criteria and concentration on the failures and defects in performance. The fourth factor is correlated with 6 factors and provides: parent`s expectations. Frost and Colleagues (1991) consider five dimensions, which could be explanatory of perfectionism concept. One of the dimensions is personal perception of parent`s expectations and their extreme criticism. Thus, parents considered being core of the malignant condition. Barva and Mora(1983 ) postulated four states that may lead to perfectionism as following:

\section{1-Openly critical and demanding parents}

2- The implications of criticizing in the parents' expectations and standards

3- Lack of criteria and standards

4-Perfectionism formation through perfectionist parent`s behavior

The fifth factor is correlated with 5 questions and shows necessity to progress. Wiseman (1980) believes: perfectionist needs progress extremely and this trend emerges in the case of high personal and unrealistic criteria (asserted by Sarvghad et al., 2011) Frost et al 1990 considered perfectionism as high criteria for performance that is defined with self-critical assessment. The sixth factor is correlated with 4 questions and shows supremacy. In this field Hornai(1950) asserts: Regarding hiding their defects, perfectionists tend to search for special solutions. He considers these solutions as: Narcissism, perfectionism, arrogance and revenge. Perfectionism solution is the shelter of individuals with high moral, logical and spiritual standards and accordingly they downgrade the others and they are proud of their perfect judgment, action and goals. Perfectionists tend to have extreme commitment and they expect to be appreciated. Supposedly, they perceive themselves as fair, honest and conscientiousness and others should notify these traits and behave accordingly. These feelings give them a sense of supremacy (asserted by Shafran \& Mansel)

Some limitations can be discussed regarding this study such as: 1) Time limitation: Reaching retest validity was really hard and Cronbach's alpha coefficient was only tool regarding assessing internal consistency of questionnaire's content and it doesn't measure the concepts such as: Reliability, predictability, repeatability and recreation. Furthermore, sampling in current study was conducted only in Tehran and it is obvious the results can't be generalized to another regions. Another limitation of this survey is that Hill perfectionism scale assesses half of factors related to perfectionism, while half of the factors related to perfectionism can`t be assessed with this scale. 


\section{Authors' contributions}

SA and MH conceived and designed the evaluation. MBM collected and interpreted the clinical data and drafted the manuscript. All authors read and approved the final manuscript.

\section{Acknowledgements}

We would like to thank all patients who participated in the study.

\section{Declaration of interest}

None declared

\section{REFERENCE}

Abolghasemi, Amoli,Kiamarsinad Azar 2007 Relationship between met cognition and perfectionism and psychological consequences of drug addicts. Behavioral Sciences, 5, 2 (10), 78-73

Atari, 2011Dimensions of perfectionism and self-regulation in predicting students' goal orientations. Knowledge and Research in Applied Psychology, 14, 2 (52), 108-100

Beshart, Karami, Sareh and Ezheye(2010)Comparison of perfectionism personality characteristics and controlling students in gifted and regular schools. Research in the area of Exceptional Children, 10, 80-65.

Frost, R. O., Heimberg, R. G., Holt, C. S., Mattia, J. I., \&Neubauer, L. A. (1990). A comparison of two measures of perfectionism. Personality and Individual Differences, 14, 119-126.

Frost, R. O., Marten, P., Lahart, C., \& rosenblate, R. (1991). The Dimension of perfectionism. Cognetive therapy and research, 15, 27-33.

Haidarali, 2001, Multivariate statistical analysis of behavioral research (printing). Tehran: Parsa

Hamuchek, D. E. (1987). Psychodynamics of normal and neurotic perfectionism. Psychology, 15, 27-33.

Hewit, P. L., \&Flett, G. L. (1991). Perfectionism in the self and social context: Conceptualication, assessment and association with social context: Conceptualication, assessment and association with psychopathology. Personality and social psychology, 60, 456-470.

Hill, R. W., Huelsmann, T. J., Furr, R. M., Kibler, J., Vicente, B. B., \& Kennedy, C.(2004). A new measure of perfectionism Inventory. Journal of Personality Assessment, 82,80-91 .

Hollender, M. H. (1965). Perfectionism. Comprehensive psychiatry, 6,94-103.

Jamshidi, Barzegar2009, Relationship between personality characteristics and dimensions of perfectionism and coping skills of male and female among Shiraz University students. Quarterly Journal of the Sociology of Women, 2, 3, 101-81.

Pasha, Salehi, Imamipoor, Bashardoost and Simin 2011, Hill perfectionism psycological features observations among the students, industrial and organizational psychology news ,7,19,9

Shafran, R., \& Mansel, W. (2001). Perfectionism psychopathology: A review of research and treatment. Clinical Psychology Review, 21, 819-906.

Stober Joachim, R. A., \& Harris, P. M. (2007). Perfectionism and the experience of pride, shame and guilt: Comparing healthy perfectionism, unhealthy perfectionism, and no perfectionism. 